\title{
The Reality Of The Controversy Surrounding The Concept Of Meaning In Semantics
}

\author{
Dr. Isaac Mhute \\ Zimbabwe Open University
}

doi: 10.19044/esj.2016.v12n5p279 URL:http://dx.doi.org/10.19044/esj.2016.v12n5p279

\begin{abstract}
This is a close analysis of the reality of the controversy surrounding the concept of meaning in semantics. Focus was basically placed on whether the so called failure to explain and disagreements on what meaning really is do exist or not. The paper assesses the so called failures of some of the popular theories explaining what meaning is in a bid to find out the truth of the matter. The paper characterises the failure or disagreement as a myth rather than a reality. It argues that there is generally not even a single one of the theories that is irrelevant as they all look at meaning from various angles and shed some very useful light on what meaning is. It is only that people tend to expect an all encompassing theory that does it all which has since proved very difficult considering the vastness of the ground covered by the concept. It suggests that people consider the theories as efforts focussing on different areas of the same aspect due to the fact that their respective proponents belong to different schools of thought.
\end{abstract}

Keywords: Meaning, Semantics, Theories of meaning

\section{Introduction}

Generally linguists define semantics as the scientific study of meaning. The merrian-webster dictionary defines semantics as the study of the meanings of words and phrases in language. Over the years this has led to the rise of various schools of thought with regard to meaning. Carnap (1974) is the main proponent of one that believes meaning to be connected with evidence and inference. Philosophers like Grice (1968) champion another one that takes meaning as a matter of the idea or feeling that an expression is used to communicate. Austin (1975) moves another school that understands meaning as having to do with speech acts that an expression can be used to communicate. Such schools of thought have led to the rise of different theories trying to account for what meaning is. Some of the theories focus on independent words, some on complete expressions whilst some 
consider both and others dwell on the relationship between expressions and the actions they trigger. Mhute et al. (2014) observe that the prevalence of so many different ways in which meaning is understood has made people treat meaning as a problematic concept.

Since the theories are by scholars who subscribe to different schools of thought and as such approach meaning from completely different angles, they are bound to concentrate on various portions of the same coin. Scholars have preoccupied themselves with dismissing every one of these theories as long as it is not satisfying the interests of the different schools of thought. This paper makes an effort to reconcile some of the theories in order to prove that there are no shortfalls in them as they are focussing on satisfying the interests of people standing at different corners of the same room. They are all trying to serve different masters and one must look at them from the point of view of the schools of thought to which their proponents subscribe.

\section{Meaning and the Referential Theory}

Referential theory is based on the assumption that language is used to talk about things outside language and claims that the meaning of a word (except a syncategorematic word) is the object it denotes, and the meaning of a sentence is the proposition it expresses (http://www.blackwellreference.com). As such, every meaningful expression has meaning because there is something that it refers to, designates, signifies, or denotes. A word is, therefore, a symbol that stands for something other than itself. The theory is also called the denotative theory of meaning. This theory generally claims that the meaning of an expression is that to which the expression refers. Words and expressions in this case are thus signals. They stand for a whole lot of concepts and activities in the external world. They are, therefore, not an end in themselves.

Various scholars have, however, dismissed it citing a number of weaknesses (Ogden and Richards, 1923; Mhute et al., 2014). For instance, a single word may have more than one referent and thus have more meanings for example 'mvura' in Shona means 'rain', 'water', 'urine' etc. Some words may refer to a single object, for example, in Shona 'gudo', 'diro', and 'bveni' all mean 'baboon'. Furthermore, there are certain words that do not have identifiable referents such as 'to', 'in' or 'Pegasus. Such words are considered meaningful but their referents are considered not identifiable. Because of such short falls, the theory is considered unable to convincingly explain what meaning is. Whilst the allegations are true, is it possible for one to completely say it has no capacity to serve as a meaningful theory of meaning? 


\section{Meaning and the Ideational Theory}

The basis of the ideational theory of meaning comes from Locke (1997) who believes that language is an instrument for communication of thought. According to Glucksberg and Danks (1975: 50), "the set of possible meanings of any given word is the set of feedings, images, ideas, thoughts and inferences that a person might produce when that word is heard and processed”. Mhute et al. (2014) consider the meaning of a word or an expression to be the thought or idea associated with that word or expression. Here the idea say of a flying horse associated with Pegasus is its meaning even if it never existed.

Criticisms in this case hinge on the fact that it is difficult to predict whether people are agreeing on a word's meaning or not (Akmajian et al., 1978). Furthermore, if the other person has never got a chance to be associated with the concept, it becomes difficult to give her the meaning of the word. However, can we really say because of this, the theory is irrelevant and worth throwing away?

\section{Meaning and the Behaviourist Theory}

Bloomfield (1933) explains language as a pattern of stimulus and response. The external world provides a stimulus and the body provides a response in the form of an action either said or done. If one sees a plate of sadza, this is the stimulus. Asking for it or taking and eating is the response and, therefore, the meaning. The idea of language and speech acts is captured correctly by the theory (Syal and Jindal, 1999). However, whilst the theory correctly brings the issue of meaning into the domain of social interactions, it is accused of falling short of explaining the definition of meaning (Mhute, et al., 2014). It has also been argued that one can utter one statement but receiving different unrelated actions in response. For instance, if one says 'Come here Chipo', she can say 'I am coming', 'You are not my boss', 'Dinner is ready', 'Pay me first'. It becomes so difficult to link the stimulus and the responses unless one has some background information. It has also been criticised for failing to explain meanings of single words as they have nothing to do with stimulus and response.

\section{Meaning and the Sense Relations Theory}

Sense is the complex system of relationships that holds between the linguistic items themselves (Syal and Jindal, 1999). The theory treats the meaning of a term as the relationship it has with the others around it. For instance, 'girl' is the synonym of 'lass' and the opposite or antonym of 'boy' etc. It thus argues that the meaning of a word hinges on the surrounding words. It proceeds to explain sentence meaning in the same way. For instance, the meaning of the sentence 'Mary kicked John' would be its 
paraphrase or passive form, for instance, 'John was kicked by Mary’.

The theory is also criticised due to its involvement of a lot of relations that may be difficult for laymen to manage. There are also possibilities of meeting people who are not aware of the various terms related to the word in question. For instance, when doing second language teaching, it will be difficult to employ such a theory as their lexicons might not have any words related to the word in question. But, again can we afford to dismiss such a theory just because it falls short in certain environments?

\section{Discussion}

The general position by linguists is that meaning is still a controversial aspect to define. However, as mentioned earlier, a close look at the theories reviewed above and their shortfalls demonstrate that they are focussing on different aspects of the concept in question. Referential theory focuses on the physical representation of language and as such clearly demonstrates the link between language and the external world. It demonstrates that the proponents' focus lies on demonstrating that link. The fact that it does not have explanations say for words without referents must not defeat its importance. It is only that it did not focus on that. This is very realistic considering the fact that even researches always admit that they have not and could not cover everything and even proceed to suggest areas for further research. The idea that there are words with more than one referent and referents with more than one word referring to them cannot be an issue as this is typical of the external world and language is meant to capture what is there. For instance, there are names being shared by many people even in the same family as well as people with more than one name. Thus this theory rightly plays its part considering the angle from which the proponents are looking at meaning and must be accepted as it is. What it left out is the task of other theories and they rightly concern themselves with just that.

The ideational theory on the other hand focuses on the mental representation of linguistic concepts and as such dwells on the thoughts, feelings or ideas linked to different words. It rightly captures the relationship that exists between what is uttered and their images that subsequently occupy our minds. It demonstrates that whilst some may want to view meaning as directly linked to the physical representation, some may also think of linking it to the mental representation and come to the same goal. This is a good demonstration of people's ability to capture what exactly transpires when they talk. Obviously when they utter a word they can point to its physical representation but at the same time some mental image is created on their mind whether they like it or not. The inability of the effect of an uttering on minds to be tested cannot defeat the good work done since 
misunderstandings will always exist between people. Degrees of intersection of conceptualisations will always vary and it is normal. An analysis of the referential and ideational theories clearly demonstrates that proponents focussed on two different relationships involved with language. The former dwells on the physical whilst the latter focuses on the mental and both do exist. It is up to the user to decide on what is best for the environment he is in rather than trying to dismiss one's work for not encroaching into the territory of the other.

Behavioural theory tries to explain meaning from yet another angle. It focuses on the speech acts that characterises language. These do exist and whatever is said depends on what has been heard, felt or seen. It is difficult to ignore the existence of such a relationship. Dismissing it because of the existence of many possible responses would again be wrong as it perfectly captures how humans behave and it is bound to happen. They differ in how they perceive things, which has generally made them very unpredictable.

Sense relations theory brings yet another angle. It demonstrates the existence of relationships between words and expressions. Just like in the external world, such relationships do exist in language. This does not come as a surprise considering the fact that language, as highlighted earlier, is just there to capture what is within and around its users. Dismissing it because of the various shortfalls identified by people who cannot apply it in certain environments would not be meaningful. Users are the ones who should decide on which one of the theories they should go for just like they do with the foods around them. Their failure to choose the one befitting their needs at some point does not warrant them the opportunity to attack that particular food.

\section{Conclusion}

The paper argues that just like any key term, scholars would define it from different angles, focussing on different aspects of it and using different words. Dictionaries always present a variety of such definitions and it is up to the consumer to choose the one that is appropriate for the situation at hand. Meaning is no different term and its definition has been similarly approached. Expecting an explanation that is all encompassing would be expecting too much as writers approach the concepts from various schools of thought.

\section{Recommendations}

It is important to credit each theory according to the best contributions that it makes and stop blowing the so-called shortfalls out of proportion as their proponents approached meaning from completely different corners of the same room. The consumer of the theory is the one 
who should decide on which approach to use at each point depending upon the task at hand.

\section{References:}

Akmajian, A. et al. 1997. Linguistics: An Introduction to Language and Communication. Cambridge: The MIT Press.

Austin, J.L. 1975. How to do Things with Words. Oxford: Oxford University Press.

Bloomfield, L. 1963. Language. New Delhi: Motilal Bunarsidas.

Carnap, R. 1974. Meaning and Necessity. Chicago: University of Chicago.

Glucksberg, S. and Danks, J.H. 1975. Experimental Psycholinguistics. Portland: Wiley and Sons, Inc.

Locke, J. 1997. An Essay Concerning Human Understanding. New York: Penguin Books.

Mhute, I. et al. 2014. Introduction to General Linguistics II. Harare: ZOU. Ogden, C.K. and Richards, I.A. 1923. The Meaning of Meaning. London: Routledge and Kegan Paul.

Syal, P. and Jindal, D.V. An Introduction to Linguistics: Language, Grammar and Semantics. New Delhi: Prentice Hall.

http://www.blackwellreference.com Accessed on 22 January 2016

http://www.merriam-webster.com/dictionary/semantics Accessed on 22 January 2016 